\title{
DIYL (do it yourself laboratories): Inovasi kit perubahan iklim untuk membentuk perilaku BROWNIS (bring your own and eat wisely) pada siswa sekolah menengah pertama (DIYL (do it yourself laboratories): Innovation of climate change kit to shape behavior of BROWNIS (bring your own and eat wisely) for junior high school's student)
}

\author{
Shafira Rizka Amani ${ }^{1 *}$, Ida Kaniawati ${ }^{1}$, Riandi $^{2}$ \\ ${ }^{1}$ Program Studi S2 Pendidikan IPA Sekolah Pascasarjana Universitas Pendidikan Indonesia, Jl. Dr. Setiabudhi No. 229 Bandung \\ ${ }^{2}$ Departemen Pendidikan Biologi FPMIPA Universitas Pendidikan Indonesia, Jl. Dr. Setiabudhi No. 229 Bandung \\ *Corresponding author: shafirra09@student.upi.edu
}

Received: 10 Auguts 2021 - Accepted: 1 September 2021 - Published: 30 September 2021

\begin{abstract}
The purpose of this article were to offer the idea of the use of climate change kit in learning to form good habits that slowly encourage the formation of environmentally friendly behaviors to reduce the increasingly high rate of global warming. Formal education is a strategic sector that can be used to spread global warming issues. Incoorperating suitable learning tools in global warming subject is the right step to provide an understanding of global warming to students in science subjects. The most concrete experiences are direct learning experiences of students. To provide hands-on experience, students can be given science teaching aids. The unity of these props is put together and packed into one container so that the props can be called a kit. There have been many studies on learning tools, various kinds of research have stated that the use of teaching aids has a positive impact on learning. The method used is a literature study. The theme of the SDGs used in the research is climate change action which is goal number 13 (climate action). The output of this idea is the formation of behavior that cares for the environment through understanding the concept of global warming which is learned using a climate change kit.
\end{abstract}

Keywords global warming, climate change kit, sustainability behavior

ABSTRAK Penelitian ini bertujuan untuk menawarkan gagasan penggunaan kit perubahan iklim dalam pembelajaran agar membentuk kebiasaan baik yang lambat laun mendorong terbentuknya perilaku peduli lingkungan untuk menekan laju pemanasan global yang semakin tinggi. Pendidikan formal merupakan sektor strategis yang dapat dimanfaatkan untuk mensosialisasikan permasalahan pemanasan global. Memasukkan perangkat pembelajaran yang cocok dalam materi pemanasan global merupakan langkah yang tepat untuk memberikan pemahaman pemanasan global kepada siswa dalam mata pelajaran IPA. Pengalaman yang paling konkrit adalah pengalaman belajar siswa yang didapatkan secara langsung. Untuk memberikan pengalaman langsung, siswa dapat diberikan media alat peraga IPA. Kesatuan dari alat peraga ini disatukan dan dikemas ke dalam satu wadah maka alat peraga tersebut dapat disebut dengan kit. Telah banyak dilakukannya penelitian mengenai perangkat belajar, berbagai macam penelitian menyebutkan bahwa penggunaan alat peraga memberikan dampak yang positif dalam pembelajaran. Metode yang digunakan ialah studi literatur. Tema SDGs yang digunakan dalam penelitian adalah aksi perubahan iklim yang merupakan tujuan nomor 13 (climate action). Keluaran dari gagasan ini ialah terbentuknya perilaku yang peduli lingkungan melalui pemahaman konsep pemanasan global yang dibelajarkan menggunakan kit perubahan iklim.

Kata kunci pemanasan global, kit perubahan iklim, perilaku berkelanjutan

\section{PENDAHULUAN}

Keadaan bumi saat ini sangat memprihatinkan. Banyak terjadinya bencana-bencana alam seperti banjir, naiknya permukaan air laut, perubahan iklim, krisis pangan global serta krisis keuangan dan ekonomi yang sedang berlangsung saat ini merupakan contoh isu - isu keberlanjutan yang harus dihadapi oleh masyarakat kita di dunia global. Perubahan iklim, krisis pangan global serta krisis keuangan dan ekonomi yang sedang berlangsung saat ini merupakan contoh isu-isu keberlanjutan yang harus dihadapi oleh masyarakat kita di dunia global. Sebagai makhluk yang memanfaatkan semua sumber daya dunia, kita wajib bertanggung jawab atas keberlanjutannya untuk generasi masa. Dalam mempersiapkan anak-anak untuk mengatasi tantangan secara efektif dari dunia yang semakin saling bergantung, sekolah memainkan peran penting dalam mengembangkan dan menerapkan metode Education for Sustainable Development (ESD). Dengan kata lain, pendidikan merupakan fondasi utama untuk pembangunan berkelanjutan.

Konsep pembangunan berkelanjutan muncul sebagai tanggapan terhadap kekhawatiran yang berkembang mengenai dampak masyarakat manusia terhadap lingkungan alam. Permasalahan lingkungan hidup dan pembangunan yang semakin kompleks ini perlu ditangani secara global. Maka dari itu, Perserikatan Bangsa-Bangsa (PBB) pada tahun tahun 1987 mulai menggali konsep pembangunan berkelanjutan melalui World Commission on Environment and 
Development (WCED) yang berjudul "Our Common Future" atau yang dikenal juga dengan nama lain yaitu "Brundtland Report", mengacu kepada nama Ketua WCED saat itu, Gro Harlem Brundtland. Konsep pembangunan berkelanjutan didefinisikan sebagai "pembangunan yang mencukupi kebutuhan masa kini tanpa mengorbankan kemampuan generasi mendatang dalam memenuhi kebutuhan mereka sendiri" (Perserikatan Bangsa-Bangsa, 1987) ("... development that meets the needs of the present without compromising the ability of future generations to meet their own needs"). Definisi tersebut menunjukan bahwa selama pemenuhan kebutuhan hidup dan meningkatkan kualitas hidup di masa sekarang, kita sangat dilarang untuk menghabiskan kapasitas lingkungan alam dan harus selalu berfikir tentang kelestarian alam untuk generasi di masa datang. Gerakan pembangunan berkelanjutan selalu menyerukan tentang melindungi kepentingan generasi masa depan dan kapasitas bumi untuk beregenerasi.

Sebagai makhluk yang memanfaatkan semua sumber daya dunia, kita wajib bertanggung jawab atas keberlanjutannya untuk generasi masa depan. Dalam mempersiapkan anak-anak untuk mengatasi tantangan secara efektif dari dunia yang semakin saling bergantung, sekolah memainkan peran penting dalam mengembangkan dan menerapkan metode Education for Sustainable Development (ESD) (Widayanti, 2019). Dengan kata lain, pendidikan merupakan fondasi utama untuk pembangunan berkelanjutan.

Pendidikan formal merupakan sektor strategis yang dapat dimanfaatkan untuk mensosialisasikan permasalahan pemanasan global. Memasukkan perangkat pembelajaran yang cocok dalam materi pemanasan global merupakan langkah yang tepat untuk memberikan pemahaman pemanasan global kepada siswa dalam mata pelajaran IPA (Santoso, 2011). Ilmu Pengetahuan Alam (IPA) adalah pengetahuan yang diperoleh melalui pengumpulan data dengan eksperimen, pengamatan, dan deduksi untuk menghasilkan suatu penjelasan tentang sebuah gejala yang dapat dipercaya.

Tingkat pengalaman yang paling tinggi nilainya adalah pengalaman yang paling konkrit sedangkan yang paling rendah adalah pengalaman yang paling abstrak. Pengalaman yang paling konkrit adalah pengalaman belajar siswa yang didapatkan secara langsung. Untuk memberikan pengalaman langsung, siswa dapat diberikan media alat peraga IPA. Alat peraga IPA dalam proses pembelajaran IPA memegang peranan penting yaitu sebagai alat bantu untuk menciptakan proses pembelajaran IPA yang efektif. (Sudjana, 2011) Untuk itu, pemilihan media atau perangkat perlu dilakukan agar didapatkan media yang baik dan tepat yang sesuai dengan kebutuhan dan kondisi siswa.

Edgar Dale memandang bahwa nilai media pembelajaran dalam pembelajaran diklasifikasikan berdasarkan pengalaman belajar menurut tingkat dari yang paling konkrit ke yang paling abstrak (Dahar, 2011). Kerucut pengalaman dari Edgar Dale menggambarkan klasifikasi pengalaman dari tingkat yang paling konkrit ke tingkat yang paling abstrak yaitu pengalaman langsung, observasi, partisipasi, demonstrasi, wisata, TV, Film, radio, simbol visual, dan simbol verbal (Susiana \& Riyana, 2007).
Pengetahuan siswa akan semakin abstrak apabila pesan yang disampaikan melalui kata verbal. Oleh sebab itu, sebaiknya siswa diberikan pengalaman secara konkrit agar pesan yang ingin disampaikan benar-benar dapat mencapai sasaran dan tujuan.

Alat peraga dipakai untuk melakukan percobaan akan menjadikan pembelajaran menjadi lebih berarti. Beberapa alat peraga dalam percobaan memiliki satu kesatuan yang terpadu terkait suatu konsep. Jika kesatuan dari alat peraga ini disatukan dan dikemas ke dalam satu wadah maka alat peraga tersebut dapat disebut dengan Kit. Kit merupakan peralatan yang diproduksi dan dikemas dalam bentuk kotak unit pengajaran, yang menyerupai rangkaian peralatan uji coba keterampilan proses pada bidang studi IPA (sains) (Trisdayanti, 2015). Media Kit IPA berfungsi sebagai pengantar pesan kepada peserta didik sehingga peserta didik dapat memahami konsep dari pengalaman yang dilakukannya. Faktor inilah yang menjadi penyebab mereka lebih cepat memahami materi yang diajarkan (Indriani et al., 2017). Penggunakan media pembelajaran dapat memudahkan peserta didik untuk mengkonstruksikan pengetahuan dan pikirannya terhadap konsep abstrak tersebut. Media sangatlah membantu dalam proses pembelajaran (Shelawaty et al., 2016).

Beberapa penelitian terkait alat peraga diantaranya: 1) penelitian Chou et al. (2015), alat bantu pengajaran dalam penelitian memberikan manfaat pembentukan sikap yang positif dan peningkatan pengetahuan pada pembelajaran energi terbarukan terkait perilaku hemat energi dan pengurangan karbon; 2) Penelitian Sukarno \& Sutarman (2014), Alat peraga refleksi cahaya yang telah dikembangkan memiliki tingkat kesesuaian, kenyamanan, dan attractiveness(daya tarik) tinggi yang cocok digunakan untuk materi fisika SMK dan SMA; 3) penelitian Saputri \& Dewi (2014), alat peraga sederhana eye lens dapat menumbuhkan keterampilan proses sains peserta didik serta efektif digunakan dalam proses pembelajaran; 4) penelitian Hamdani et al. (2012), terdapat pengaruh model pembelajaran generatif menggunakan alat peraga sederhana terhadap pemahaman konsep cahaya di SMP Negeri 7 Kota Bengkulu; 5) penelitian Sari et al. (2014), alat peraga sederhana dapat membantu siswa dalam memahami materi listrik dinamis. Alat peraga yang dirancang dilengkapi dengan modul penuntun praktikum untuk memudahkan siswa dalam memahami penggunaan alat peraga sederhana; 6) penelitian Presetyarini et al. (2013) menunjukkan bahwa pemanfaatan alat peraga IPA dapat meningkatkan pemahaman konsep fisika siswa pada pokok bahasan pengukuran di SMP Negeri 1 Buluspesantren Kebumen Tahun Pelajaran 2012/2013 sehingga pemanfaatan alat peraga IPA dapat dijadikan alternatif guna meningkatkan pemahaman konsep fisika. Dari beberapa pemaparan penelitian tersebut dapat disimpulkan bahwa penggunaan alat peraga memberikan dampak yang positif dalam pembelajaran (Widayanti, 2019).

\section{METODE}

Metode penelitian menggunakan studi literatur yaitu peneliti menelaah secara tekun akan kepustakaan yang diperlukan dalam penelitian (Nazir, 2014, p. 79). 
HASIL

\section{DIYL (Do It Your Self Laboratories): Inovasi Kit Perubahan Iklim}

Climate Change Kit yang sudah ada meliputi oceans rising, create winds, test for carbondioxide dan acid emissions. Inovasi kit DIYL (Do It Yourself Laboratories) pada materi pemanasan global ialah sebagai berikut:

Penambahan dua buah balon dan korek api (untuk memperihatkan kepada siswa bahwa air mengabsorpsi panas):

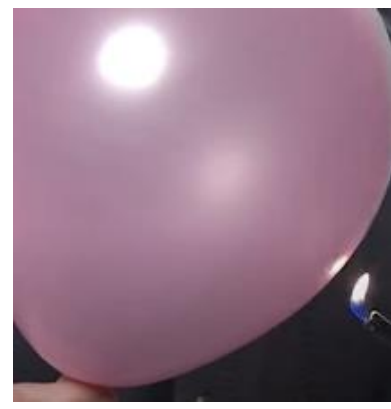

a

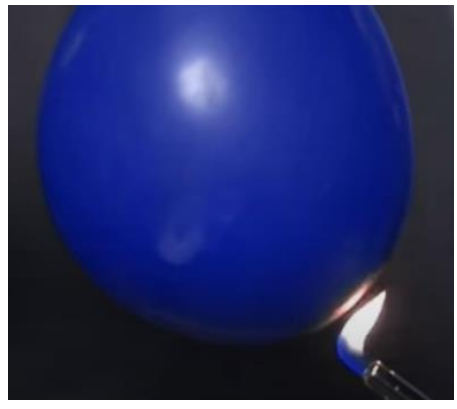

b
Gambar 1. a) Balon tidak berisi air (balon yang hanya berisi udara pecah seketika); b) Balon berisi air (panas diabsorpsi oleh air sehingga balon tidak pecah)

Penambahan dua buah botol, thermometer, baking soda, dan lampu belajar (untuk memperlihatkan perbandingan secara langsung bahwa jumlah karbondioksida yang banyak dapat menyebabkan suhu lebih panas):

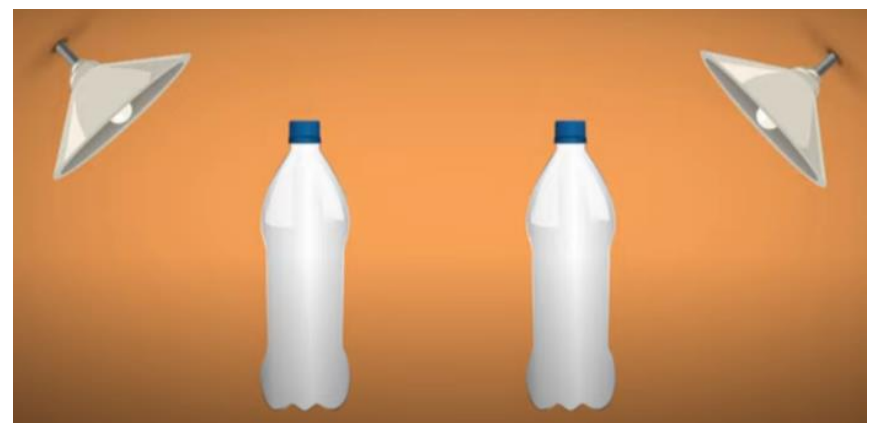

Gambar 2. Rancangan kit karbondioksida

Climate Change Kit meliputi oceans rising, create winds, test for carbondioxide dan acid emissions.

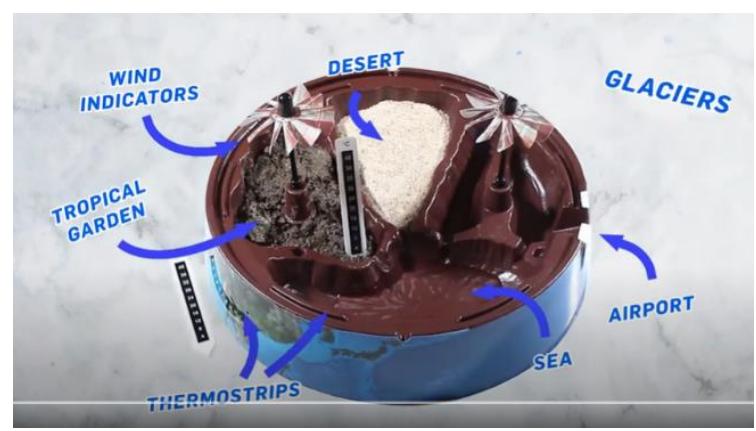

Gambar 3. Climate Change Kit

\section{BROWNIS (Bring Your Own and Eat Wisely)}

Setelah siswa diperkenalkan dengan konsep pemahaman global dan menyadari pentingnya menjaga bumi, siswa diarahkan untuk selalu menggunakan wadah makanan dan minuman sendiri serta makan makanan dengan cukup (tidak berlebih).
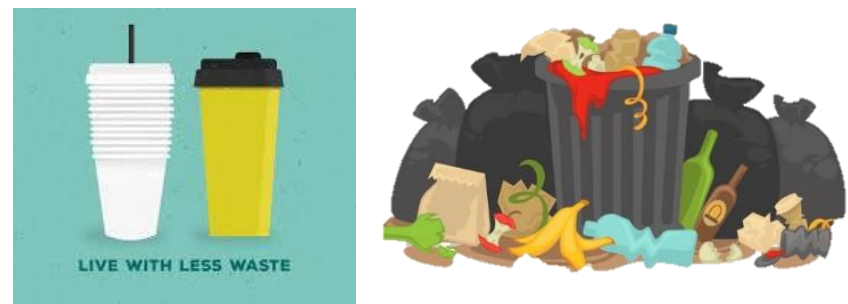

Gambar 4. BROWNIS (Bring Your Own and Eat Wisely)

\section{SIMPULAN}

Diharapkannya dengan gagasan DIYL (Do It Yourself Laboratories): Innovation Climate Change Kit to shaping behavior BROWNIS (Bring Your Own and Eat Wisely) for Student in Junior High School membawa perubahan yang baik sesuai tujuan SDG's poin ke-13 (Climate Change Action). Jika penggunaan Kit belajar DIYL Climate Change diharapkan mampu membentuk kesadaran, siswa memahami perannya sebagai agen penjaga lingkungan, dan membentuk kebiasaan-kebiasaan baru yang peduli terhadap lingkungan melalui pembelajaran materi pemanasan global salah satunya BROWNIS.

\section{REFERENSI}

Chou, Y. C., Yen, H. Y., \& Yen, H. W. (2015). The Effectiveness of Teaching Aids for Elementary Students' Renewable Energy Learning and an Analysis of Their Energy Attitude Formation. International Journal of Environmental \& Science Education, 10(1), 39-49.

Dahar, R. W. (2011). Teori-teori Belajar \& Pembelajaran. Jakarta: Erlangga.

Hamdani, D., Kurniati, E., \& Sakti, I. (2012). Pengaruh Model Pembelajaran Generatif dengan Menggunakan Alat Peraga terhadap Pemahaman Konsep Cahaya Kelas VIII di SMP Negeri 7 Kota Bengkulu. Jurnal Exacta, 10(1), 79-88.

Indriani, E., Sahputra, R., \& Hadi, L. (2017). Pengembangan Media Komponen Instrumen Terpadu (KIT) Ikatan Kimia. Jurnal Pendidikan dan Pembelajaran UNTAN, 6(10).

Nazir, M. (2014). Metode Penelitian. Jakarta: Ghalia Indonesia.

Perserikatan Bangsa-Bangsa. (1987). Report of the world commission on environment and development: Our common future. https://sustainabledevelopment. un.org/content/documents/5987our-commonfutur e.pdf

Santoso. (2011). Pengembangan materi geografi integrasi pemanasan global (global warming) dengan metode problem-based learning pada kelas XI di SMAN 1 Suruh Kabupaten Semarang. Jurnal PP 1 (1).

Saputri, V. A. C. \& Dewi, N. R. (2014). Pengembangan alat peraga sederhana eye-lens tema mata kelas VIII untuk menumbuhkan keterampilan peserta didik. Jurnal Pendidikan IP A Indonesia, 3(2), 109-115. 
Sari, D. N., Lizelwati, N., \& Eliwatis. (2014). Pengembangan alat peraga praktikum sederhana dan modul penuntun praktikum untuk materi listrik dinamis pada pelajaran fisika kelas X sma. Edusainstika, 1(1), 18-20.

Shelawaty, A. R., Hadiarti, D., \& Fadhilah, R. (2016). Pengembangan media flash materi ikatan kimia siswa kelas X. Ar-Razi Jurnal Ilmiah, 4(2), 11-22. http://dx.doi.org/10.29406/arz.v4i2.670

Sudjana, N. (2011a). Dasar-dasar Proses Belajar Mengajar. Bandung: Sinar Baru Algensindo

Sudjana, N. (2011b). Penilaian Hasil Proses Belajar Mengajar. Bandung: PT Remaja Rosdakarya.

Sukarno dan Sutarman, D. (2014). The development of light reflection props as a physics learning media in vocational high school number 6 Tanjung Jabung Timur. International Journal of Innovation and Scientific Research, 12(2), 346-355

Trisdayanti, P. (2015). Motivasi Belajar Siswa dalam Belajar IPA dengan menggunakan Media KIT di kelas tinggi (Skripsi) Universitas Negeri Gorontalo, Gorontalo.

Widayanti, R, Cari, Sarwanto. (2019). Pengembangan Media Pembelajaran Kit pada Materi Kemagnetan untuk Meningkatkan Aktivitas, Motivasi, dan Prestasi Belajar IPA Siswa SMP Kelas IX SMPN 1 Nguntoronadi. Jurnal Pendidikan IP A, 7(3), 333-350.

Conflict of Interest Statement

The author(s) declare that the research was conducted in the absence of any commercial or financial relationships that could be construed as a potential conflict of interest.

How to Cite

Amani, S.R., Kaniawati, I., \& Riandi (2021). DIYL (do it yourself laboratories): Inovasi kit perubahan iklim untuk membentuk perilaku BROWNIS (bring your own and eat wisely) pada siswa sekolah menengah pertama. Assimilation: Indonesian Journal of Biology Education, 4(2), 89-92. 